\title{
Capsule Commentary on Albrecht et al., Hospital Discharge Instructions: Comprehension and Compliance Among Older Adults
}

\author{
Hyo Jung Tak, PhD \\ Department of Health Management and Policy, University of North Texas Health Science Center, Fort Worth, TX 76107, USA.
}

J Gen Intern Med 29(11):1529

DOI: $10.1007 / \mathrm{s} 11606-014-2966-\mathrm{y}$

(c) Society of General Internal Medicine 2014

\begin{abstract}
A lbrecht et al. used data collected from elderly patients at a tertiary care facility and found that patient demographics and discharge diagnoses are associated with noncomprehension of and noncompliance with hospital discharge instructions. ${ }^{1}$

This is an interesting and important study as the comprehension of and compliance with discharge instructions could reduce ER visits or re-hospitalizations, improve postdischarge health outcomes, and decrease health care expenditures. ${ }^{2}$ In particular, the Medicare Payment Advisory Commission has estimated that $\$ 12$ billion is spent annually for potentially avoidable readmissions. ${ }^{3}$ While researchers and medical practitioners have put forth substantial effort to design and implement comprehensive inpatient education and discharge planning to improve comprehension and compliance, they rarely examine patient characteristics associated with noncomprehension and noncompliance. ${ }^{2}$ This study provides valuable insight into identifying the high-risk target population; using this information as a policy lever could improve the effectiveness of interventions to enhance comprehension and compliance.
\end{abstract}

Their analytic approach warrants discussion. First, the authors examined the association between the outcome variable and explanatory variable in a bivariate analysis and included only significant variables in their regression analysis. This is hard to reconcile because the notion of ceteris paribus - that is, holding all other factors fixed - is the crux of measuring a true relation of interest. Furthermore, given that individual characteristics such as demographics, socioeconomic status, and health status might be correlated, excluding any potentially correlated variables could result in estimation bias. ${ }^{4}$ It might have been helpful to confirm that their model specification was appropriate had they performed post-estimation tests, such as sensitivity analysis and multiple testing. Second, the compliance was measured at 5 days of discharge. This may not reflect the true nature of noncompliance as it tends to decrease over time and long-term compliance would be more critical in patients' health outcomes and expenditures. $^{5}$

Integrating this study's findings with the effect of medical provider attributes (e.g., primary care vs. surgical care) and physician-patient relationships (e.g., quality of communication) may motivate further study.

Conflict of Interest: The author has no conflicts of interest with the material in this article.

Corresponding Author: Hyo Jung Tak, PhD; Department of Health Management and Policy, University of North Texas Health Science Center, Fort Worth, TX 76107, USA (e-mail: hyojung.tak@unthsc.edu).

\section{REFERENCES}

1. Albrecht JS, Gruber-Baldini AL, Hirshon JM, Brown CH, Goldberg R, Rosenberg JH, Comer AC, Furuno JP. Hospital discharge instructions: comprehension and compliance among older adults. J Gen Intern Med. 2014. (Article \#2956)

2. Hansen L, Young R, Hinami K, Leung A, Williams M. Interventions to reduce 30-day rehospitalization: a systematic review. Ann Intern Med. 2011;155:520-528.

3. MedPAC. Payment Policy for Inpatient Readmissions. Report to the Congress: Reforming the Delivery System. Washington, DC: Medicare Payment Advisory Commission; 2007.

4. Wooldridge J. Econometric analysis of cross section and panel data. Cambridge: MIT press; 2010;3:66-67.

5. Friedrich M, Gittler G, Halberstadt Y, Cermak T, Heiller I. Combined exercise and motivation program: effects on the compliance and level of disability of patients with chronic low back pain: a randomized controlled trial. Arch Phys Med Rehabil. 1998;79:475-487. 